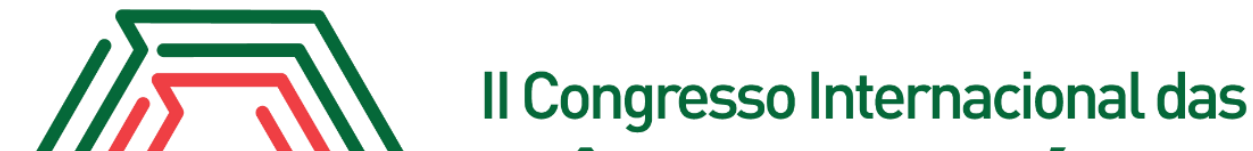 Ciências Agrárias COINTER - PDVAgro 2017
}

\section{ANÁLISE DA PERCEPÇÃO AMBIENTAL EM DUAS DIFERENTES TURMAS DO ENSINO BÁSICO DE ESCOLA PÚBLICA E PRIVADA, BELÉM -PA}

Apresentação: Pôster

Daniela Samara Abreu das Chagas ${ }^{1}$; Samara Thais da Costa Pinheiro ${ }^{2}$; Fiama Kelly Melo Nunes $^{3}$; Jôsy Mylena de Brito Santos ${ }^{4}$; Mário Lopes da Silva Junior ${ }^{5}$

\section{Introdução}

A percepção ambiental pode ser compreendida como o primeiro estágio para a formação do conhecimento e da conscientização ambiental (CANEPA, 2004), convém atentar que a educação ambiental está intimamente ligada ao individuo como ser social, portanto é importante a percepção individual (DIAS, 2016). Nos últimos anos muito se tem falado sobre a necessidade da preocupação com o meio ambiente, dessa forma é inevitável que as crianças, principalmente as do ensino básico sejam os "grandes alvos" para as atividades que influenciam na formação da educação ambiental, pois teoricamente é a classe que mais recebera o ensinamento de modo a perpetua-lo em sua geração, devido a pouca idade e a percepção sobre o meio não está definida. Carpi Junior et al (2014) destacam que a percepção ambiental é capaz de refletir características interpretativas do ser humano pautadas em experiências. Abreu (2013), Afirma que a forma de abordagem da Educação Ambiental no Ensino Fundamental das Escolas Públicas e privadas é predominantemente interdisciplinar.

Portanto, o presente estudo objetivou-se fazer uma análise comparativa da percepção ambiental de discentes do ensino básico de duas turmas; uma da escola publica e outra privada, avaliados através de questionário e visita na Universidade Federal Rural da Amazônia para ampliar o conhecimento dos alunos acerca do tema visando com que estas experiências tenha valor preponderante na educação ambienta dos mesmos.

\footnotetext{
${ }^{1}$ Engenharia Florestal, Universidade Federal Rural da Amazônia, dsamaraabreu@hotmail.com

2 Engenharia Florestal, Universidade Federal Rural da Amazônia, samarathaiscosta@gmail.com

${ }^{3}$ Engenharia Florestal, Universidade Federal Rural da Amazônia, fiamamelo10@outlook.com

${ }^{4}$ Engenharia Ambiental, Universidade Federal Rural da Amazônia, josimbsantos@gmail.com

${ }^{5}$ Doutor em Agronomia, Universidade Federal Rural da Amazônia, mario.silva@ufra.edu.br
} 


\section{Fundamentação Teórica}

$\mathrm{Na}$ atual conjuntura há uma preocupação cada vez maior para com o meio ambiente, há muitos trabalhos mostrando a percepção ambiental nas escolas, principalmente com alunos muito jovens, fazendo comparativos entre instituições publicas e privadas, buscando avaliar as diferenças presentes. Segundo Dias (2016), posições críticas sobre a problemática do meio ambiente representavam um setor que, embora tenha muita penetração entre os educadores, não se consolida como hegemônicas na organização do sistema de ensino. Tozoni-reis (2012), afirma que Muitos estudos apontam a fragilidade da inserção da educação ambiental na escola pública no Brasil, contudo, a educação ambiental ainda sim constitui-se em um importante caminho na educação escolar, como meio para conscientizar e superar os efeitos do uso indiscriminados dos recursos naturais no planeta.(ABREU, 2013).

\section{Metodologia}

A pesquisa foi realizada na cidade de Belém - PA, ocorreu no período de agosto de 2017 a setembro do mesmo ano com duas escolas, uma de ensino público - Escola Estadual Virgílio Libonati -, situada nas dependências da universidade Federal Rural da Amazônia e a outra de ensino privado - Colégio São Paulo -. Foram escolhidas turmas do quarto ao sexto ano do ensino básico com faixa etária de idade de 9 a 12 anos. Para a análise da percepção ambiental e problemas relacionados ao assunto foi aplicado um questionário estruturado com 9 perguntas objetivas e subjetivas, sendo aplicados 16 questionários na Escola Virgílio Libonati e 24 questionários no Colégio São Paulo. Após a aplicação do questionário foi realizada uma visita na Universidade Federal Rural da Amazônia - UFRA, uma ação organizada pelo Programa de Educação Tutorial, PET - solos, que é composto por 12 integrante de três cursos, sendo: Engenharia florestal, Agronomia e Engenharia ambiental. A ação ocorreu em diferentes datas para cada escola, os alunos fizeram a visita com o auxilio do micro ônibus da própria universidade, dividido em quatro paradas durante o trajeto que foram: $1^{\mathrm{a}}$ parada - prédio de solos, onde foi dividida as atividades nos Laboratórios de Microbiologia do Solo, Química do Solo e foram utilizados minerais e rochas, mostruário de solo para demonstração da formação do solo desde seu material de origem até seu estágio final, sua importância e os impactos do manejo inadequado do solo através de uma mini palestra, logo após levados a trincheira para o contato físico, onde foram distribuídas luvas de plástico para o contato com o solo e auxilio para avaliação da granulometria do solo e para visualizarem as camadas do solo. No laboratório de química foi demostrado a importância do 
nutrientes para o solo e planta, além da demonstração da física do solo, usando 3 diferentes tipos de solo e água, para ilustrar a importância da camada de vegetação e a mineralogia do solo; $2^{\mathrm{a}}$ parada projeto carroceiro, o projeto é coordenado por médicos veterinários da instituição que tem o intuito de resgatar equinos utilizados por carroceiros em situação de maus tratos para receber cuidados e ficar disponível a adoção, os alunos puderam ter contato com as animais, foram levados para conhecer este projeto, foram recebidos por uma médica veterinária que os situou sobre os fins do projeto; $3^{\mathrm{a}}$ parada - horta: fica localizada no prédio do Instituto de Ciências Agrárias - ICA, houve o recebimentos dos alunos por um professor que falou sobre a importância dos cuidados com a vegetação e sua importância na sociedade; $4^{\mathrm{a}}$ parada - Laboratório de zoologia: os discentes foram levados ao laboratório para ter o contato visual com animais taxidermizados, onde foram recebidos pela responsável do local que discorreu sobre o assunto de maus tratos com animais e seu papel no laboratório para fins de pesquisa. O tempo utilizado de ação em cada turma foi de aproximadamente de uma manhã e os dados coletados pelos questionários foram esta demostrado em forma de gráfico.

\section{Resultados e Discussões}

Para realização da pesquisa foi feita a aplicação de um questionário para os alunos das escolas Virgílio Libonati e São Paulo, foi observado que ambos os alunos tem percepção de preservação do meio ambiente (Gráfico 1), ao serem questionados se existe problemas ambientais na cidade onde vivem, apenas 1 (6,25\%) dos alunos da escola Virgílio Libonati respondeu que não, todos os alunos do Colégio São Paulo responderam que sim, também todos os alunos das duas escolas que responderam sim para essa questão disseram que esses problemas os incomodam. Ao serem questionados sobre quando um homem desmata a floresta se ele está prejudicando a natureza, apenas 1 aluno $(6,25 \%)$ da escola Virgílio Libonati respondeu que não - o que demonstra que talvez esse aluno não conheça o conceito da palavra desmatamento -, e todos os 24 alunos do Colégio São Paulo responderam que sim, que a natureza está sendo prejudicada. Ao serem questionados se a Universidade pode ajudar a cuidar do meio ambiente, $100 \%$ dos alunos de ambas escolas responderam que sim, demonstrando que enxergam a universidade como ambiente transformador. Quando questionados se as árvores que existem na universidade e na sua cidade ajudam a purificar o ar que respiramos, apenas 1 alunos de ambas escolas responderam que não. Apenas 1 aluno $(4,16 \%)$ do Colégio São Paulo não sabia o conceito da palavra desmatamento e todos os alunos da Escola Virgílio Libonati já entendem o seu significado. Para identificar problemas ambientais no 
seu bairro ou rua, 93,75\% dos alunos da escola Virgílio Libonati responderam que sim e apontaram problemas como: lixo nas ruas, esgoto a céu aberto, buracos nas ruas e alagamentos. Enquanto no Colégio São Paulo 29,17 alunos não identificaram problemas no seu bairro e 70,83\% dos alunos disseram haver problemas em seus bairros e ruas e apontaram problemas como: lixo na rua, poluição do ar pelos carros, além de desmatamento e queimadas.

Para Carvalho (2008) as práticas de Educação Ambiental comunitária ou populares estão, geralmente, muito implicadas nos processos de desenvolvimento social local, gerando maior capacidade de perceber problemas, pesar consequências ambientais das escolhas coletivas e decidir sobre a qualidade de vida das populações. Sendo assim, de acordo com as respostas das crianças que está no Gráfico 1 podemos dizer que eles já tem a capacidade de perceber os problemas ambientais e já tem uma percepção do ambiente em quem vivem.

Gráfico 1: Relação das respostas do questionário aplicado nas duas escolas expressos em porcentagem. Fonte: própria.

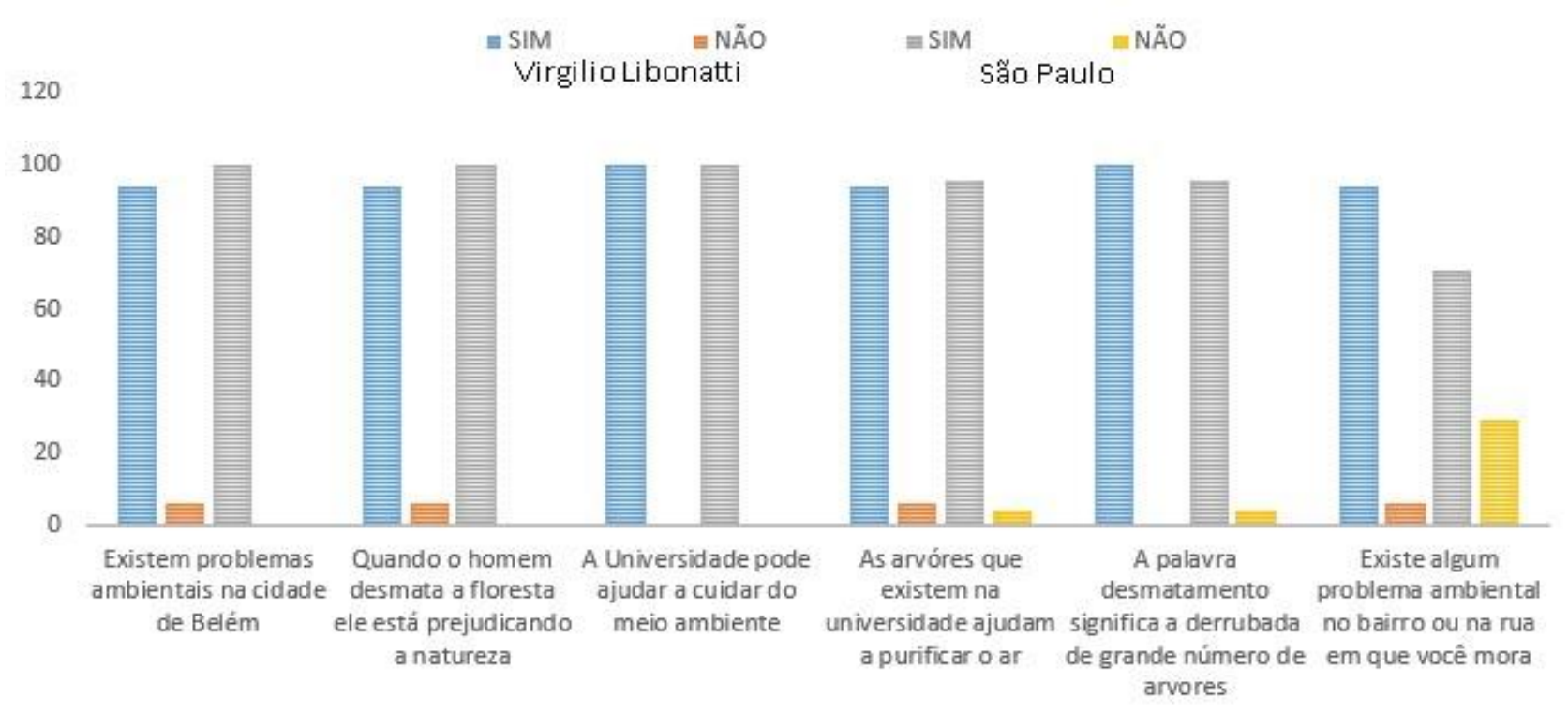

\section{Conclusões}

Pode-se concluir que a educação ambiental dos discentes avaliada através dos questionários não apresentou diferença significativa entre as duas escolas, além disso, apresentaram níveis consideráveis de preocupações e ações voltadas para a preservação do meio ambiente. Ainda sim, as visitas a universidade para as atividades de cunho ambiental são muito importante, pois estimula a 
participação dos estudantes que é uma alternativa promissora para o desenvolvimento da educação ambiental nas escolas.

Referências

ABREU, G. G.; RODRIGUES, M. A.; O tratamento de educação ambiental nas escolas públicas e privadas: Um estudo de caso nas escolas do ensino fundamental da cidade de Uruçuí-PI. Enciclopédia biosfera, Centro Científico Conhecer - Goiânia, v.9, N.16; p. 2012371, 2013.

CANEPA, C. Educação ambiental: ferramenta para a criação de uma nova consciência planetária. Revista de Direito Constitucional e Internacional. São Paulo, v. 12, n. 48, p. 158-166, jul.-set. 2004.

CARVALHO, I. C. de M. Educação ambiental: a formação do sujeito ecológico. - 4. ed. - São Paulo: Cortez, 2008.

DIAS, L. S.; LEAL, A. C.; CARPI JUNIOR, S. Educação ambiental: conceitos, metodologias e práticas. 1 Edição Tupã: ANAP, 2016.

FALCÃO, E. .; ROQUETTE, G. S. As representações sociais de natureza e sua importância para a educação ambiental: uma pesquisa em quatro escolas . Ensaio Pesquisa em Educação em Ciências, vol. 9, núm. 1, 2007, pp. 1-21 Universidade Federal de Minas Gerais Minas Gerais, Brasil.

NÓBREGA, F. M.; PASSAVANTE. J. Z. O. Educação ambiental em escolas públicas. 1 - UFPE - Departamento de Oceanografia.

SILVA, M. M. P.; Leite, V. D. Estratégias para realização de educação ambiental em escolas do ensino fundamental. Rev. eletrônica Mestr. Educ. Ambient. ISSN 1517-1256, v. 20, janeiro a junho de 2008. [

TOZONI-REIS, M. F. C. Políticas públicas para a educação no brasil: contribuições para compreender a inserção da educação ambiental na escola pública. xvi endipe - Encontro Nacional de Didática e Práticas de Ensino - UNICAMP - Campinas - 2012. 